\title{
Coğrafi İşaretler ve Tosya Yerel Çeltik Genotipleri Örneği
}

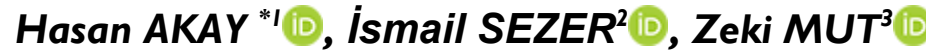

\author{
' Ondokuz Mayıs Üniversitesi, Bafra Meslek Yüksek Okulu, Bafra/Samsun \\ ${ }^{2}$ Ondokuz Mayıs Üniversitesi, Ziraat Fakültesi, Atakum/Samsun \\ ${ }^{3}$ Bilecik Șeyh Edebali Üniversitesi, Ziraat ve Doğa Bilimleri Fakültesi, Merkez/Bilecik
}

Öz: Türkiye'de ilk çeltik tarımının yapıldığı Tosya İlçesi'nde kalitesi bakımından ün yapmıș “Tosya Pirinci” üretilmektedir. Tosya'da çeltik tarımı, Ilgaz dağlarından doğan Devrez çayının olușturduğu vadi boyunca I500'lü yıllarda bașlanmıș olup, Türkiye Cumhuriyeti'nin ilk çeltik ișleme fabrikası da 1925 yılında burada kurulmuștur. Tosya 1980'li yıllarda ülkemizdeki çeltik üretiminin yaklașık \%5'ini karșılarken, günümüzde bu oran sadece \%0.07’e kadar gerilemiștir. Yeni çeșitlerin ıslah edilmesi ve bașka ekim bölgelerinin ortaya çıkması gibi faktörler geçmiște çeltik yetiștiriciliğiyle anılan Tosya'da birim alan veriminin düșük kalmasına neden olmuștur. Ancak Tosya pirinci Türkiye'nin en lezzetli pirinci olarak kabul edilmektedir. Bu nedenle, bu kültürel mirasın koruma altına alması ve gelecek nesillere tașınmasında coğrafi ișaretin alınması büyük katkı sağlayacaktır. Tosya pirincine coğrafi ișaret alınmasıyla Tosyalı çiftçinin emeğinin korunmasına, ekim alanının artmasına, tüketicilerin bölgenin kültürü hakkında bilgi sahibi olmasına ve ișletmelerin sürdürülebilirliğine olanak sağlanacaktır. Türk Patent Enstitüsü'nde pirinç olarak, Gönen Baldo Pirinci, Karacadağ Pirinci, İpsala Pirinci, Tosya Pirinci, Bolu Kıbrıscık Pirinci, Konuralp Pirinci ve Maraș Sarı Çeltik Pirinci bașvuruları bulunmaktadır. Bunlardan İpsala Pirinci ve Tosya Pirinci tescili kabul edilmiș; Gönen Baldo Pirinci bașvurusu ise reddedilmiștir.

Anahtar Kelimeler: Coğrafi ișaret, çeltik, Sarıkılçık, Tosya

\section{Geographical Indications and Sample Genotypes of Local Paddy of Tosya}

Abstract: Paddy cultivation in Turkey, where the first district in Tosya a reputation for quality "Tosya Rice" is produced. Cultivation of paddy in Tosya form of stream Devrez nature of llgaz Mountain along the valley that was started in the 1500s, the first rice processing factory in the Republic of Turkey was founded here in 1925. As Tosya met nearly $5 \%$ of the paddy production in the country in 1980s, today it has only declined to $0.07 \%$. Factors such as the reclamation of new varieties and the emergence of other planting zones have led to a low yield per unit area in Tosya, which is known for its rice growing in the past. However Tosya rice is regarded as Turkey's most delicious rice. For this reason, it is necessary to take a geographical indication in order to protect this cultural heritage and to carry it to future generations. By taking the Tosya rice geographical indication, it will be possible to protect the labor of the Tosyal farmer, to increase the planting area, to inform the consumers about the culture of the region and to the sustainability of the enterprises. In Turkish Patent Institute, there are applications for Gönen Baldo Rice, Karacadağ Rice, Ipsala Rice, Tosya Rice, Bolu Kıbrıscik Rice, Konuralp Rice ve Maraș Yellow Rice. In this application, Gönen Baldo Rice application was rejected while the Ipsala Rice and Tosya Rice were accepted.

Keywords: Geographical indication, paddy, Sarıkılçı, Tosya

\section{GiRiș}

Coğrafi ișaretler, kalite veya diğer belirgin özellikleri bakımından coğrafi kökeni olan, belirli bir bölgeyi temsil eden sınaî mülkiyet hakkıdır (Ilıcalı, 2005). Yöreye özgü bu ürünler; uzun yıllarda olușan birikim ve tecrübesiyle bölge ve ülke kalkınmasında önemli rollere sahiptir. Dünya Ticaret Örgütü'ne 1995 yılında üye olmasıyla birlikte Türkiye, Avrupa Birliği'nin coğrafi ișaretlere ilișkin 208I//992 sayılı Konsey Tüzüğünden esinlenilerek, 555 sayılı Coğrafi İșaretlerin Korunması Hakkında Kanun Hükmünde Kararnameyi (KHK) kabul etmiștir. Ülkemizde kırsal kalkınma çalıșmaları son yıllarda ivme kazanmıștır. Ülkemizde yerel ürünlere ayrıcalık yaratmasında ve bu ürünlerin kırsal ekonomiye katkısının yükselmesinde "Coğrafi ișaretler" önemli bir basamaktır (Kan ve Gülçubuk, 2008). Coğrafi ișaretler, tarım ürünleri, insan eliyle yapılan ürünler, maden ve sanayi ürünleri gibi çok farklı ürünleri kapsamaktadır. Ülkemizde coğrafi ișarete konu olan tarım ürünleri bakımından 69 tanesi tescillenmiș olup 94 adet bașvuru așamasında beklemektedir.

\section{COĞRAFi IȘARETLI ÜRÜNLER}

Coğrafi ișaretler, kendi içinde “menșe adı" ve "mahreç ișareti” olarak iki gruba ayrılmaktadır.

Menșe Adı: Ürünün üretimi ve ișlenmesi tamamı, kesin olarak belirlenmiș coğrafi alanda ise buna menșe adı denir. Menșe adı alan ürünlerin temel özelliği kesin olarak sınırı çizilmiș bir coğrafi alandan olmalarıdır. Bu ürünlere, Erzincan tulum peyniri, Isparta gülü, Kayseri pastırması ve Pervari balı örnek verilebilir. Menșe adı alan ürünler, özellik ve kalitelerini ancak, ait oldukları coğrafyanın kültürel özellikleri ile üretildikleri takdirde kazanabilirler (Çalıșkan ve Koç, 2012; Şahin ve Meral, 2012).

Mahreç ișareti; Ürünün en göze çarpan özelliği ya da diğer özellikleri itibarıyla coğrafi bölge ile bağdașması, ürünün üretim ve ișleme gibi uygulamalardan birinin, sınırları

Sorumlu Yazar: hasan.akay@omu.edu.tr

Geliș Tarihi: 3 Kasım 2017

Kabul Tarihi: 7 Kasım 2018 
çizilmiș coğrafi bölgede olan coğrafi ișaretlere verilen isimdir. Mahreç ișaretine sahip ürünün tanımlanan özelliklerden en az birini bulundurması halinde ise coğrafi sınırları dıșında da üretilebilir. Yani, mahreç ișareti alan ürünler bașka yerlerde de üretilebilmekte olup, tescil edildikleri coğrafi bölgeye ait ham madde ve üretim așamalarının aynen yapılması zorunludur. Mahreç ișaretli ürünün belirlenen kalitesinin aynı olması zorunludur (Anonim, 2016a). Mahreç ișaretine sahip olan bazı örnekler ise; Çorum leblebisi, Gaziantep baklavası, Antakya künefesi, Kula el halısı, Trabzon telkariye ve hasırdır.

Coğrafi ișaretlerin tescilinin yapılmasıyla, yöresel bilgi ve kültürel mirasın korunması, yerel üretim desteklenerek kırsal kalkınma, kültürel turizmin gelișmesi ve ürün taklitçiliği ile mücadelenin sağlanması amaçlanmaktadır.

Bir ürün adı, tüketiciler tarafından tanınmıș özgünlüğe sahip olmasının yanı sıra hammadde temini ve ișleme așamaları belirlenmiș coğrafi alanda, ayrıntılı șekilde tanımlanmıș olması gibi temel özelliklere sahip olan ürünler coğrafi ișaret alarak tescillenmektedir.

Ürünün üreticisi olan gerçek ya da tüzel kișiler, tüketici dernekler ve ilgili kamu kurumları tescil bașvurusunda bulunabilirler (Demirer, 20l0).

Coğrafi ișaret tescili olan ürünlerin kalitesinin, üreticisinin ve ürün standardının tescil koruması haklarından yararlanmaları gerekmektedir. Coğrafi ișaret almıș ürünler, tek bir üreticiyi değil, șartları sağlayan tüm üreticileri korumaktadır. Coğrafi ișaretle tescillenen ürün bulunduğu bölgede anonim özelliğe sahiptir (Anonim, 2016a).

Coğrafi ișaretleri en önemli kılan unsur küreselleșmeye karșı yerel hareketleri teșvik ederek kırsal kalkınmayı sağlamasıdır. Coğrafi ișaretlerin kırsal kalkınma için sağladığı avantajlar beș bașlıkta incelenebilir (Kop ve ark., 2006; Kan, 2007).

a. Koruma aracı; Üreticilerin sahte olarak üretilen ürünlerden dolayı haklarının çalınmasını ve tüketicilerin ise kandırılmasını engelleyen bir unsurdur.

b. Pazarlama aracı; Ürünün halka arzı sırasında imajını ve șöhretini olumlu yönde etkilemektedir.

c. Kırsal kalkınma aracı; Yerel ișletmelerin ve kırsal bölgelerde kültürel mirasın devamlılığı ile biyoçeșitliliğin korunması amacıyla kullanılmaktadır.

d. Ekonomik bir denge aracı; Gelișmemiș bölgeler ile gelișmiș bölgelerin arasındaki ekonomik dengesizliği ortadan kaldırmakta kullanılmaktadır.

e. Bilgi aracı; Üretici ile tüketici arasında kültürel bilginin ve mirasın paylașımını sağlayan önemli bir bilgi aracıdır. Özellikle ürünleri tüketen kișilerin sadece ürünler hakkında değil, üretim bölgesinin kültürü hakkında da bilgi sahibi olmasına imkan vermektedir.

Coğrafi ișaret tesciline bașvuran toplam 2500 adet üründen sadece 430 adedi tescile hak kazanmıștır. 329 adet ürünün tescil süreci devam etmektedir. Ancak $|74|$ adet ürün tescile uygun bulunmamıștır. Türkiye'de tescil edilen ürünlerin geçerliliği ülke sınırları içindedir. Coğrafi işaret bașvuru ve tescil sayıları ilișkin veriler çizelge l'de incelendiğinde yıllar içerisinde tescillenen ürün sayısının artığı gözlenmiștir (Anonim, 20l6a).

82
Çizelge I. Yıllara göre coğrafi ișaret bașvuru ve tescil sayıları (Anonim, 2016a)

\begin{tabular}{c|cc}
\hline \multirow{2}{*}{ Yıllar } & \multicolumn{2}{|c}{ Coğrafik İșaret } \\
\cline { 2 - 3 } & Bașvuru Sayısı & Tescil Sayısı \\
\hline 2010 & 35 & 19 \\
2011 & 87 & 16 \\
2012 & 140 & 20 \\
2013 & 46 & 12 \\
2015 & 64 & 24 \\
2016 & 84 & 15 \\
2017 & 72 & 8 \\
2018 & 173 & 66 \\
\hline
\end{tabular}

Günümüze kadar Türk Patent Enstitüsü’ne pirinç ürünü için 7 adet coğrafi ürün ișareti bașvurusu yapılmıștır. Bunlar; Gönen Baldo Pirinci (c2009/04I), Karacadağ Pirinci (c2010/059), İpsala Pirinci (c2012/070), Tosya Pirinci (c2014/069), Bolu Kıbrıscık Pirinci (c2016/072), Konuralp Pirinci (c2016/056) ve Maraș Sarı Çeltik Pirinci (c2016/088)'dir. Bu bașvurulardan İpsala Pirinci (c2012/070) ve Tosya Pirinci'nin (c2014/069) tescili kabul edilmișken, Gönen Baldo Pirinci (c2009/04I) reddedilmiștir.

Tosya çeltiği, pirinç rengi, aroması ve lezzeti ile asırlardır bölgede yașayan insanların damağına hitap etmektedir. Bölge halkı tarafından kalitesi, görünümü, lezzeti ile son derece kabul görmüș olan Tosya köy çeșidi pirinç ișleme sektörünün de dikkatini çekmektedir. Öyle ki bölge halkı Tosya pirincinin olduğu yerde diğer çeșitlere ait pirinci tüketmemektedir. Tosya çeltiği tarlada kendine özgü bir morfolojiye sahiptir. Tosya pirinci diğer pirinçlerin aksine, dane yapısından ayırt edebildiği için coğrafi ișaret almıștır.

\section{TOSYA YEREL ÇELTIK GENOTIPLERI}

Tosya çeltiğinin kalite özellikleri hakkında detaylı bilgi yazılmamıștır. Ayrıca Tosya'da yetiștirilen ve metinde geçen çeșitler ile ilgili yapılan çalıșmalardan bahsedilmemiștir. Örneğin Șavșatlı ve ark. (2004) tarafından Samsun șatlarında yürütülen araștırmada, Tosya'da adı geçen çeșitler yetiștirilmiș, ancak hastalık nedeniyle tek bitki verimlerinde büyük düșüșler görülmüștür. Samsun'a adapte olamayan bu çeșitler kendi esas yerinde (Tosya'da) problem olmadan yaygın olarak yetiștirilebilmektedir. Bu sonuç, coğrafik ișaret konusunda makaleyi desteklemektedir. Dolayısıyla, bu ve benzer makalelere yer verilerek literatür sayısının da artırılmasında fayda bulunmaktadır.

Bitki ıslahı çalıșmalarının temelini genetik tabanın zenginliği meydana getirmektedir. Yerel genotipler ya da ilkel formlar kültür bitkilerinin genetik taban olarak yeni karakterlerin aktarılmasında en önemli gen kaynaklarıdır. Yerel genotip yada popülasyon bir bölgenin veya alanın koșullarına uzun yıllar içinde uyum sağlamıș olup, çiftçiler tarafından benimsenmiștir. Uzun yıllar ekolojik faktörlerin etkisi ile bölgeye uyum sağlayan ve üretici tarafından benimsenen genotipler "yerel genotip" olarak adlandırılmaktadır. Bölge ekolojik koșullarına uygun çeltik çeșitlerinin geliștirilmesi, 
bölge çeltik üretimine ve ülke ekonomisine önemli katkıda koșullardan kritik yılları ya da dönemleri en az olumsuzluk ile atlatabilmeleri ve en önemlisi ise alıșkanlıklara sahip tüketici isteklerini karșılayan kalite özellikleri ile vazgeçilmezdir. Islah yöntem ve teknolojisi ne olursa olsun, yeni çeșitlerin geliștirilmesinde yerli gen kaynakları önemini sürekli koruyacaktır.

Buğdaygiller (Gramineae) familyasının Oryzae oymağına giren çeltik, oldukça eski bir kültür bitkisidir. Güneydoğu Asya'da özellikle Hindistan ve Çin'deki kültür formları zenginliği nedeniyle, Oryza cinsinin gen merkezinin bu ülkeler olduğu görüșü yaygındır. Çeltiğin kültürü yapılan ilk iki tipi Oryza sativa ve Oryza glaberrima olarak ileri sürülmektedir. Oryza cinsine 21 yabani tür dahildir. İlk olarak M.Ö. 3000'li yıllarda yetiștiriciliği yapılan çeltik, Avrupa'ya Ortaçağ'da gelmiștir. Daha sonrasında Araplar tarafından Kuzey Afrika'ya, ardından İspanya ve Fransa'nın güney bölgesine yayılmıștır. Türkiye'de ise çeltik tarımının yaklașık 600 yıllık bir geçmișinden bahsedilmekte olup, üretimin ilk olarak nerede ve ne zaman bașladığına dair kesin bir kanıt yoktur. Anadolu'ya 15. yüzyılda Mısır'dan gemiler ile gelerek güney bölgelerinden girdiği ve ilk ekim yapılan yerler arasında Kastamonu İli'nin Tosya İlçesi'nin olduğuna dair görüșler hakimdir (İbret, 2004a; İbret, 2004b; Avcı, 2012).

Osmanlı İmparatorluğu kayıtlarına göre; 16. yüzyılda Tosya'da çeltik tarımının ve I7/9-I720 yıllarında Tosya șehrinden ilk pirinç ihracatının yapıldığı belirtilmektedir. 16.
AKAY H, SEZER İ, MUT M bulunacağı kușkusuzdur. Yerel çeltik genotipleri, iklimsel yüzyıla ait kayıtlarda da Anadolu'nun pirinç merkezleri arasında Beypazarı, Niksar ve Boyabat'la birlikte Tosya'nın da adı geçmektedir (Kankal, 1992). Bu kayıtlarda Devrez Çayı boyunca uzanan vadi tabanında padișah hassı (Padișah Sofrası) olarak ayrılmıs olan lezzetli pirinçlerin elde edilmesi için çeltik üretiminin yapıldığı bildirilmektedir (İbret, 2004a; 2004b). Türkiye'de 1926 yılında ilk çeltik fabrikası Tosya'da kurulmuș (İbret, 2004a); Cumhuriyet'in ilanı yapılmadan önce Bursa, Diyarbakır, Kastamonu ve Kahramanmaraș illerinde çeltiğin yetiștiriciliğinin yapıldığı ve elde edilen pirincin ise İstanbul gibi büyük șehirlerdeki zengin ailelerce tüketildiği bildirilmiștir (Șahin, 2002).

Türkiye'de 1930 yılında çeltik üretiminin \%।4'ü Tosya'dan karșılanırken 1960 yılına gelindiğinde bu pay \%3.5'e, 2000'de \%2.l'e ve günümüzde ise \%0.7'ye düșmüștür (Șekil I) (Anonim, 2016b). 1980'li yıllara kadar adı çeltik yetiștiriciliğiyle özdeșlesen Tosya'nın, yeni çeșitlerin ıslah edilmesi, bașka ekim bölgelerinin ortaya çıkması ve modernleșen tarım tekniklerine ayak uyduramaması gibi nedenler birim alan veriminin düșük kalmasına ve ülke genelindeki üretim payının azalmasına neden olmuștur. Ancak çeltik verimi düșük olsa da hala Türkiye'nin en lezzetli pirinci olarak kabul edilmektedir. Günümüzde, Tosya'da yetiștirilen bașlıca çeltik çeșitler arasında Sarı Kılçık (\%45), Ak Çeltik (\%5), Maratelli (\%5), Yașar (\%25) ve Osmancık-97 (\%20) çeltik çeșitleri yer almaktadır.

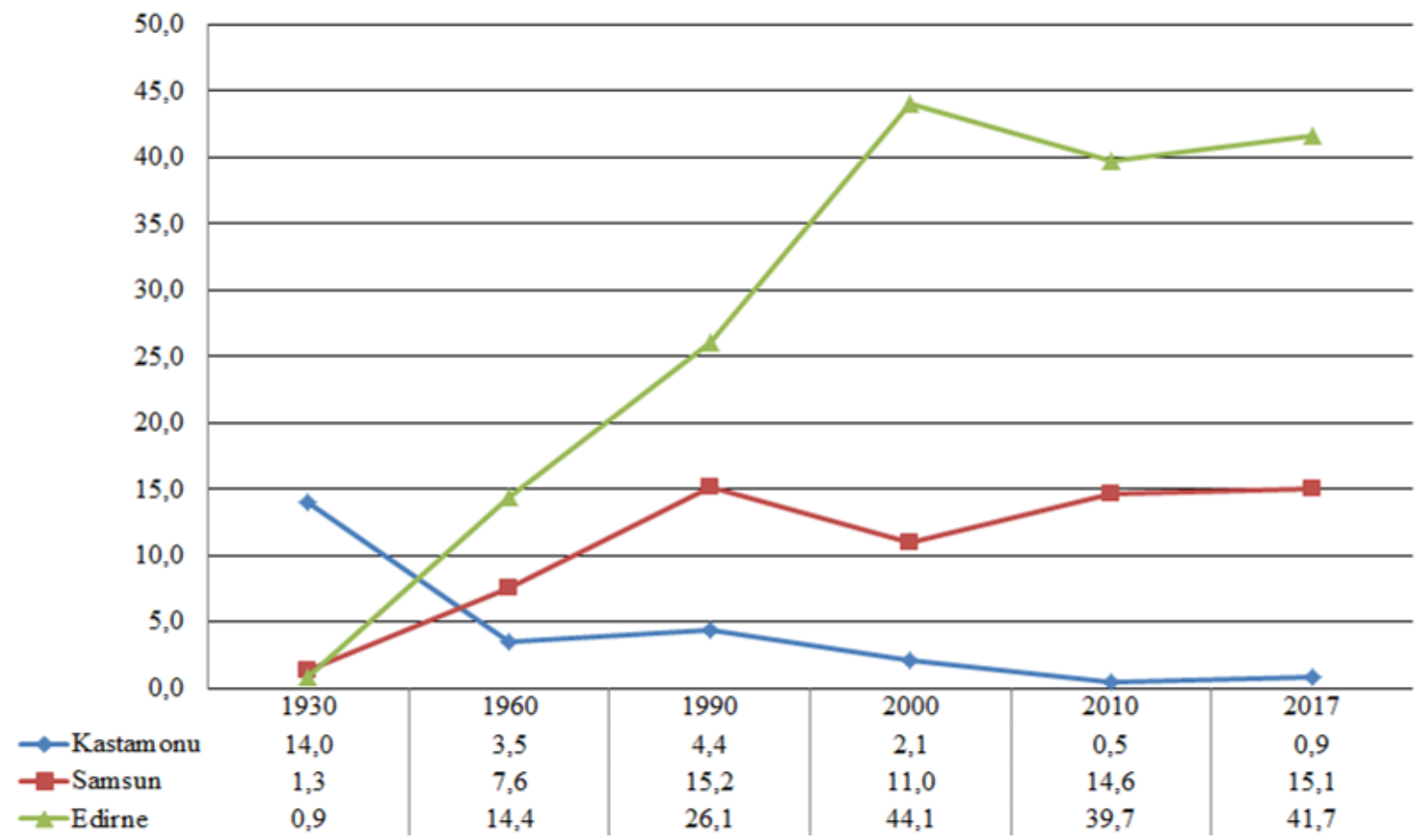

Șekil I. Türkiye çeltik üretimindeki Kastamonu, Samsun ve Edirne illerinin payları

Çeltik, Tosya İlçesi sınırları içinde tarla tarımı açısından en kıymetli üründür. Ancak Kastamonu ilinin yöresel çeltik yetiștiriciliği açısından çok önemli ekolojik yapıya sahip olmasına rağmen, bölge için tescil edilmiș yada üretim izni alınmıș bir çeșidi yoktur. Bölge üreticileri populasyonları kullanmakta olup, verim ve kalite açısından stabil bir durum olmadığı için populasyonlarının morfolojik olarak tanımlanması gerekmektedir (Akay ve ark., 20I3).

Türkiye'nin çeltik üretim alanlarına bakıldığında Karadeniz Bölgesi çeltik tarımı için ikinci sırada yer almaktadır. 
Karadeniz bölgesinde özellikle Gökırmak, Devrez, Kızılırmak ve Yeșilırmak gibi akarsuların suladığı vadi ve ovalarda çeltik tarımı yapılmaktadır. Devrez vadisine bakıldığında Tosya İlçesi'ni ikiye ayırarak olușturduğu sulak alanlarda çeltik tarımı yapılmaktadır. Tosya'nın doğusunda yer alan așağı devrez vadisi çeltik üretiminde ilk sırayı alırken, batısında yukarı devrez vadisi ikinci sırada yer almaktadır (Akay ve ark., 2013).

Devrez vadisin de yükseltinin 400-700 marasında değiștiği taban alanlarda çeltik üretimi yapılmaktadır. Yukarı Kayı ve Dağardı'ndan bașlayıp, Çifter, Karacabey, Suluca, Çepni, Tosya Merkez, Kösen, Sapaca, Çaykapı, Yenidoğan, Çevlik ve Ortalıca köylerini içine alan devrez çayı boyunca uzanan vadide (yaklașık $45 \mathrm{~km}$ uzunluk), 450 - 770 metre rakım ve 400541 - 4l0 031 $K$ ve 33047 - 340 I81 $D$ enlem ve boylamları arasında yetiștiricilik yapılmaktadır.

Tosya yöresinde engebeli alanlarda eriyen kar sularını tașıyan Devrez vadisinde yetiștirilen çeltiklerden elde edilen pirincin damak tadı, sulama suyu olarak kullanılan Devrez çayı'nın çizelge 2'de görülen içeriğe sahip olmasındandır. Periyodik olarak alınan su örneklerinde yapılan ölçümlerde su sıcaklığı minimum $12{ }^{\circ} \mathrm{C}$, maksimum $24^{\circ} \mathrm{C}$ ölçülmüș ve çeltik yetiștiriciliği için uygun aralıkta olduğu tespit edilmiștir.

Çizelge I. Yıllara göre coğrafi ișaret bașvuru ve tescil sayıları (Anonim, 2016a)

\begin{tabular}{|c|c|c|c|c|c|c|c|c|c|c|c|c|}
\hline & $\begin{array}{l}\mathrm{KOI}^{*} \\
\mathrm{mg/l}\end{array}$ & $\begin{array}{l}\mathrm{BOI}^{*} \\
\mathrm{mg} / \mathrm{l}\end{array}$ & $\begin{array}{c}\mathrm{NH}_{4}-\mathbf{N}^{*} \\
\mathrm{mg} / \mathrm{l}\end{array}$ & $\begin{array}{c}\mathrm{NO}_{3}-\mathbf{N}^{*} \\
\mathrm{mg} / \mathrm{l}\end{array}$ & $\begin{array}{l}\text { TP* } \\
\text { mg/l }\end{array}$ & $\begin{array}{c}\mathrm{Na} \\
\mathrm{mg} / \mathrm{l}\end{array}$ & $\begin{array}{c}\mathrm{Cl} \\
\mathrm{mg} / \mathrm{l}\end{array}$ & $\begin{array}{l}\mathrm{SO}_{4} \\
\mathrm{mg} / \mathrm{l}\end{array}$ & $\begin{array}{l}\text { TÇM* } \\
\text { mg/l }\end{array}$ & $\mathrm{pH}$ & $\begin{array}{c}\text { EC } \\
\mu S / m\end{array}$ & DOi* \\
\hline $\begin{array}{l}\text { Ölçüm } \\
\text { Değeri }\end{array}$ & 23.5 & 4.98 & 0.185 & 3.89 & 0.02 & 8.51 & 6.52 & 2.25 & 449 & 7.86 & 648 & 6.35 \\
\hline Sinifi** & 1 & I-II & I- II & I & II & I & II & I & I-II & II & II & I-II \\
\hline
\end{tabular}

* KOİ: Kimyasal Oksijen İhtiyacı, BOİ: Biyolojik Oksijen İhtiyacı, NH4-N: Amonyum Azotu, NO3-N: Nitrat Azotu, TP: Toplam Fosfor, TÇM: toplam Çözünmüș Madde, DOİ: Doymuș Oksijen; ** Sınıf I: Yüksek kaliteli Sınıf II: Kaliteli su (Tuncay, 1994)

Tosya yerel genotipi erkenci bir çeșit olup soğuğa dayanıklıdır. Kavuz ve kılçıkları kırmızımtrak koyu sarı renkte olan, bitki boyu bakımından uzun boylu olmasına rağmen yatmaya karșı tepkisi iyi ve verimliliği orta durumda olan, orta taneli yerel çeșittir. Kırıksız pirinç randımanı \%5060 civarında olup, damak tadı bakımından kendine özgü tadı ve aroması olan yerel bir genotiptir. Türk Gıda Kodeksi Pirinç Tebliğine göre orta taneli pirinç sınıfındadır.

Üretim metodu bakımından Tosya çeltiği yetiștiriciliğini diğer bölgelerden ayıran en önemli özellik, tesviye ișlemi için diğer bölgelerde lazerli makineler kullanırken bölgede keșan adı verilen ağaçtan yapılmış alet kullanılmasıdır. Ayrıca keșanlama yapılan tavalardaki toprağın saturasyon haline gelmesi, ardından da ön çimlendirme yapılmıș çeltiklerin elle serpme yöntemiyle ekilmesi en önemli bir farklılıktır. Ayrıca çeltik kurutma ișleminin diğer bölgelerde olduğu gibi makine yardımıyla değil güneș ya da gölgede kurutma yöntemleri ile yapılmasıdır.

\section{SONUC}

Türkiye, coğrafi konum bakımından coğrafi ișaret potansiyeli çok yüksek olan bir bölgedir. Yüksek coğrafi ișaret potansiyeline sahip olmasına rağmen günümüze kadar 329 adet farklı ürün tescil edilmiștir. Tescil süreci devam eden 430 adet ürün vardır. Coğrafi ișaret potansiyeli olan ürünlerin belirlenmesinde görev alan bir kurum ya da kuruluș bulunmamaktadır. Bundan dolayı, coğrafi ișaret tescil bașvurularında genel olarak bilgi sahibi olan yerel yönetimler ve üreticiler belirleyici olmaktadır.

Tosya pirincinin menșe adını tașıması için; üretimi, ișlemesi gibi tüm ișlemlerinin tamamıla $40^{\circ} 54^{\prime}-4 I^{\circ} 03^{\prime} \mathrm{K}$ ve $33^{\circ} 47^{\prime}$ - 340 18' D enlem ve boylamları arasında olması gereklidir. Coğrafi ișaret alınmasıyla;

- Koruma aracı; Tosyalı çiftçinin emeği korunacak,
- Pazarlama aracı; Pazardaki imajı ve șöhreti olumlu yönde artacak,

- Kırsal kalkınma aracı; ișletmelerin sürdürülebilirliği sağlanacak,

- Ekonomik bir denge olușturma aracı; Daha karlı bir satıș yapılacak ve ekim alanının artması sağlanacak,

- Bilgi aracı; Üretici ile tüketici arasında kültürel bilginin ve mirasın paylașımını sağlayan önemli bir bilgi aracı olacaktır.

\section{KAYNAKLAR}

Akay H, Sezer I, Mut Z, İmamoğlu B, Sarı H, Sarıbaș O (20I3) Tosya İlçesindeki Geleneksel Çeltik Üretiminin İrdelenmesi. Türkiye 10. Tarla Bitkileri Kongresi, I0-13 Eylül 2013, Konya, 394-397.

Anonim (2016a) http://www.tpe.gov.tr. (Erișim tarihi: 10.06.2016).

Anonim

https://biruni.tuik.gov.tr/bitkiselapp/bitkisel.zul. (Erișim tarihi: 10.06.2016).

Avcı C (2012) 19. yüzyıl Sonlarında Kastamonu Vilayeti. Abant İzzet Baysal Üniversitesi Sosyal Bilimler Enstitüsü Dergisi I: 24-26.

Çalıșkan V, Koç H (2012) Türkiye'de Coğrafi İșaretlerin Dağılıș Özelliklerinin ve Coğrafi İșaret Potansiyelinin Değerlendirilmesi. Doğu Coğrafya Dergisi 28:193-2।4.

Demirer H R (2010) Yöresel Ürün ve Coğrafi İșaretler. Fransa ve Türkiye Üzerine Bir İnceleme. Doktora Tezi, Akdeniz Üniversitesi, Antalya.

llıcalı G (2005) Coğrafi İșaretler, Coğrafi İșaretlerde Denetim ve Denetimde Akreditasyonun Önemi. Ankara Üniversitesi Avrupa Toplulukları Araștırma Uygulama Merkezi (ATAUM) 36. Dönem Avrupa Birliği Temel Eğitim Programı Semineri, Ankara. 
İbret BÜ (2004a). Tosya Șehrinin Fonksiyonel Özellikleri. Marmara Coğrafya Dergisi 9:1-40.

İbret BÜ (2004b) Tarihi İpek Yolu Üzerindeki Bir Anadolu Șehri Tosya (Kurulușu ve Gelișmesi). Marmara Coğrafya Dergisi 8: I-30.

Kan M (2007) Kırsal Kalkınmada Coğrafi İșaretler ve Bazı Ülkelerden Uygulama Örnekleri. Doktora Semineri, Ankara Üniversitesi, Ankara.

Kan M, Gülçubuk B (2008) Kırsal Ekonominin Canlanmasında ve Yerel Sahiplenmede Coğrafi İșaretler. VIII. Tarım Ekonomisi Kongresi, 25-27 Haziran208, Bursa, 225-230.
Kankal A (1992) 16. yüzyılda İdârîliktisâdî ve Sosyal Açıdan Kargı Kazâsı. Ankara Üniversitesi Osmanlı Tarihi Araștırma ve Uygulama Merkezi Dergisi 3:223-245.

Kop P, Van DE, Sautier D, Gerz A (2006) Origin Based Products. Lessons for Propoor Market Development. Royal Tropical Institute - CIRAD, 372:225-228.

Șahin A, Meral Y (20I2) Türkiye'de Coğrafi İșaretleme ve Yöresel Ürünler. Türk Bilimsel Derlemeler Dergisi 5(2): 88-92.

Șahin S (2002) Tosya-Osmancık ve Kargı ilçelerinde Çeltik Ziraatı. Gazi Üniversitesi Gazi Eğitim Fakültesi Dergisi 22(3): 19-35.

Tuncay H (1994) Su kalitesi (I. Basım). Ege Üniversitesi Ziraat Fakültesi, İzmir. 
